\title{
Hypercholesterolemia and tissue-specific differential mRNA expression of type-1 5'-iodothyronine deiodinase under different selenium status in rats
}

\author{
SANJIV DHINGRA and MOHINDER P BANSAL
}

Department of Biophysics, Panjab University, Chandigarh, India.

\begin{abstract}
Type-1 5'-iodothyronine deiodinase (5'-DI) is responsible for conversion of $\mathrm{T}_{4}$ to $\mathrm{T}_{3}$. Selenium (Se) is an integral part of this enzyme. Keeping in view the strong association between atherosclerosis and hypothyroidism, the present study examined the behavior of 5'-DI in liver, aorta and thyroid during hypercholesterolemia following different Se status, i.e., Se deficiency $(0.02 \mathrm{ppm})$, adequate $(0.2 \mathrm{ppm})$ and excess dose (1ppm) in SD male rats. Animals were fed a control or high-cholesterol diet (2\%) for 1 and 2 months. 5'-DI activity and mRNA expression was measured by RIA and RT-PCR respectively. In liver and aorta, 5'-DI expression significantly decreased with the Se-deficient and the high-cholesterol diet. The trend was opposite in thyroid, i.e., mRNA expression increased significantly during selenium deficiency and with a high-cholesterol feeding. But with 1ppm Se supplementation, the 5'-DI expression increased in all the three tissues. The present study indicates that hypercholesterolemia along with selenium deficiency is coresponsible for differential regulation of 5'-DI enzyme in thyroidal vs. extrathyroidal tissues. Distinct regulation of 5'-DI in the thyroid reflects the clinical importance of this selenoprotein during hypercholesterolemia as this enzyme is essential for $\mathrm{T}_{3}$ production, which further has a vital role in the maintenance of lipid metabolism.
\end{abstract}

Key terms: selenium, hypercholesterolemia, 5'-DI, cholesterol, RT-PCR.

\section{INTRODUCTION}

Type-1 5'-iodothyronine deiodinase (5'-DI) has a pivotal role in controlling the supply of $\mathrm{T}_{3}$ (the biologically active form of thyroid hormone) to the tissues. Under normal circumstances, more than $80 \%$ of plasma $\mathrm{T}_{3}$ is derived from 5'-monodeiodination of $\mathrm{T}_{4}$ (Vander Geyten et al., 2005), mainly in the liver and kidney, where this reaction is catalyzed by 5'-DI (Alvarez et al., 2005). Thyroid also express 5'-DI activity, and studies have shown that it is identical to the hepatic 5'-DI (Green, 1978). The activity of 5'-DI has been shown to be decreased in a hypothyroid state and elevated during hyperthyroidism (Wassen et al., 2004).

Selenium (Se), an essential element and potent antioxidant, has an important role in the control of thyroid hormone metabolism.
Evidence from animal, clinical and in vitro cell culture studies suggested a clear Sedependent expression of 5'-DI varying with Se availability (Korhle, 1999). As selenium is an integral part of this enzyme (Behne et al., 1990; Berry et al., 1991), 5'-DI activity rapidly decreases with Se deficiency (Backett et al., 1987).

Hypercholesterolemia has been shown to induce hypothyroidism (Wojcicki et al., 1991; Frank et al., 2004). Thyroid hormones $\left(\mathrm{T}_{3}\right.$ and $\mathrm{T}_{4}$ ) have a vital role in the maintenance of normal lipid metabolism, and abnormal thyroid status can lead to biochemical and pathological changes that are potentially injurious to the cardiovascular system (Pingitore et al., 2005). Studies have demonstrated that almost $10 \%$ of asymptomatic hypercholesterolemic patients have subclinical hypothyroidism 
(Michalopoulou et al., 1998). Thyroid hormone replacement therapy improved the cardiac function in several patients (Siegmund et al., 2004). Several studies indicate that Se deficiency is associated with hypercholesterolemia (Kang et al., 2000; Lee et al., 2003). Keeping in view the important role of $\mathrm{Se}$ in hypercholesterolemia and its association with 5'-DI, the purpose of present study was to explore the response of 5'-DI enzyme in liver, aorta and thyroid under different Se status during experimental hypercholesterolemia.

\section{MATERIALS AND METHODS}

\section{Animals}

Male Sprauge-Dawley rats (100g-body weight) were used in the present study. Animals were obtained from the Central Animal House, Panjab University, Chandigarh.

\section{Treatment Protocol}

Animals were acclimatized to the laboratory animal room and initially divided into three groups: group I (Se-deficient diet fed); group II (Se-adequate diet fed); and group III (Seexcess diet fed). Feed and water were given ad libitum. This Se diet was given to the animals for 10 days in order to achieve the required Se status. The animals in these three groups were further divided into two each, viz.: group Ia (Se-deficient control), group Ib (Se-deficient + high-cholesterol diet fed); group IIa (Se-adequate control), group IIb (Se-adequate + high-cholesterol diet fed); group IIIa (Se-excess control), group IIIb (Seexcess + high-cholesterol diet fed). Treatment protocol was for 1 and 2 months.

\section{Diet preparation}

Se deficient diet: Yeast-based synthetic Sedeficient diet $(0.02 \mathrm{ppm} \mathrm{Se})$ was prepared in the laboratory (Burk, 1987). It contained torula yeast (inactivated) $30 \%$, sucrose $56.99 \%$, corn oil $6.67 \%$, mineral mix $5 \%$, vitamin mix $1 \%$, dlmethionine $0.3 \%$ and vitamin E $0.04 \%$.

Se-supplemented diets: Se-adequate and Se-excess diets were prepared by supplementing the Se-deficient diet with
$0.2 \mathrm{ppm}$ and $1 \mathrm{ppm}$ of Se as sodium selenite (Sigma Chemicals).

High-cholesterol diet (HCD): $2 \%$ of cholesterol (Loba-Chemie, India) was added to the respective diets of the HCD groups.

After completion of the diet feeding schedule, the rats were kept on fasting for $10 \mathrm{hrs}$, anesthetized and exsanguinated. Serum and tissue (liver, aorta and thyroid) samples were collected from each animal. Tissues were snap frozen in liquid nitrogen. Serum total cholesterol and triglycerides levels were estimated by enzymatic colorimetric kits obtained from HUMAN Gmbh (Germany). Various parameters were evaluated as detailed below.

\section{Selenium estimation}

Selenium level was estimated by fluorimetric method (Hasunuma et al., 1982), based on the principle that $\mathrm{Se}$ content in serum or tissue on acid digestion is converted to selenous acid. The reaction between selenous acid and aromatic-odiamines, such as 2,3-diaminonaphthalene (DAN), leads to the formation of 4,5benzopiazselenol, which displays brilliant lime-green fluorescence when excited at $366 \mathrm{~nm}$ in cyclohexane. Fluorescence emission in extracted cyclohexane was read on a fluorescence spectrophotometer using $366 \mathrm{~nm}$ as the excitation wavelength and $520 \mathrm{~nm}$ as the emission wavelength.

\section{Se-dependent glutathione peroxidase activity}

Glutathione peroxidase (GSH-Px) activity was assayed by the coupled enzyme procedure with glutathione reductase, using $\mathrm{H}_{2} \mathrm{O}_{2}$ as substrate (Paglia and Valentine, 1967). The assay was carried out in the postmitochondrial fraction (PMF) of liver as already published by the authors (Dhingra et al., 2003) and the activity expressed as $\mu$ moles of NADPH oxidized $/ \mathrm{min} / \mathrm{mg}$ protein. Total protein estimation was done in all the samples (Lowry et al., 1951).

\section{$T_{3}$ and $T_{4}$ levels}

Serum $\mathrm{T}_{3}$ and $\mathrm{T}_{4}$ estimation was done by radioimmunoassay (RIA) kits procured 
from BARC, Mumbai (Cat. No. RIAK-4/4A and RIAK-5/5A for $\mathrm{T}_{3}$ and $\mathrm{T}_{4}$ respectively).

\section{5'-DI activity}

5'-DI activity in liver, aorta and thyroid was estimated by radioimmunoassay (Behne et al., 1990).

\section{mRNA analysis}

5'-DI mRNA expression was analyzed in liver, aorta and thyroid by using RT-PCR kit (QIAGEN Inc., USA).

\section{RNA isolation}

Total RNA from tissues was extracted using TRI REAGENT (Molecular Research Center, Inc., Ohio, USA). The integrity and size distribution (quality) of RNA was examined by formaldehyde agarose gel electrophoresis.

\section{$R T-P C R$}

$2 \mu \mathrm{g}$ of total RNA template from the different groups after treatment with DNase I (Ambion) was used in RT-PCR reaction. To the reaction mixture, we added $10 \mu \mathrm{l}$ of $5 \mathrm{X}$ QIAGEN One Step RT-PCR buffer $(2.5 \mathrm{mM}$ $\mathrm{MgCl} 2$ as final concentration), $2 \mu \mathrm{l}$ of $\mathrm{dNTP}$ mix $(10 \mathrm{mM}$ of each dNTP), $5 \mu \mathrm{l}$ of each coding (+) and noncoding (-) gene-specific primers (from $10 \mu \mathrm{M}$ stock), $2 \mu \mathrm{l}$ QIAGEN One Step RT-PCR Enzyme Mix, $1 \mu l$ RNase inhibitor $(1 \mathrm{U} / \mu \mathrm{l})$ and, finally, $25 \mu \mathrm{l}$ of PCRgrade RNase-free water (provided in the kit) to reach a total volume of $50 \mu 1$, which was mixed gently by vortex and centrifuged. The PCR reaction was performed in the thermal cycler (Techne Ltd., England) under the following conditions: the $\mathrm{RT}$ reaction was performed at $50^{\circ} \mathrm{C}$ for $50 \mathrm{~min}$; initial PCR activation was done at $95^{\circ} \mathrm{C}$ for $15 \mathrm{~min}$, followed by 35 cycles of $94^{\circ} \mathrm{C}$ (denaturation) for $45 \mathrm{sec}, 58.8^{\circ} \mathrm{C}$ (annealing) for $45 \mathrm{sec}$, $72^{\circ} \mathrm{C}$ (extension) for $1 \mathrm{~min}$. Finally, the reaction mixture was incubated at $72^{\circ} \mathrm{C}$ for 10 min to extend any incomplete single strands.

The optimal oligonucleotide primer pair for 5'-DI was selected with the aid of software Gene Runner (Informax Ltd., USA) and primer sequences for B-actin were taken from the literature (Kimura et al., 1998). The primer sequence ( $5^{\prime}$ to $3^{\prime}$ ) for rat 5'-DI gene coding (+) strand was TCTGGGATTTCATTCAAGGC, the noncoding strand was TAGAGCCTCTCAGGCAGAGC. For rat $B$-actin, the gene coding (+) strand was AGAGCTATGAGCTGCCTGAC, and the noncoding (-) strand was CTGCATCCTGTCAGCCTACG. The lengths of the RT-PCR products were $346 \mathrm{bp}$ and $236 \mathrm{bp}$ respectively for $5^{\prime}$-DI and B-actin.

Final PCR products were analyzed on $1.5 \%$ agarose gel electrophoresis using 10 $\mathrm{mM}$ TE buffer. $5 \mu \mathrm{l}$ of PCR product was used from each tube. Densitometric analysis of the bands was done by UviBandMap software (Uvitech, England).

The above-described RT-PCR reactions for 5'-DI and 3 -actin were determined on the basis of a series of experiments to test the reaction conditions, such as amount of RNA linearity, cycle linearity, primer concentrations etc. The final RT-PCR conditions were shown to be in the linear range of amplification for both the genes.

\section{Statistical analysis}

Data is expressed as mean $\pm \mathrm{SD}$. Difference between different groups was tested using student's t-test for unpaired values.

\section{RESULTS}

\section{Selenium levels}

Selenium levels in the serum and liver decreased significantly $(\mathrm{p}<0.001)$ in $\mathrm{Se}$ deficient groups (Ia and $\mathrm{Ib}$ ) and increased in $1 \mathrm{ppm}$ Se-supplemented diet fed groups (IIIa and IIIb) in comparison to the respective adequate groups (IIa and IIb). Significant decrease $(p<0.001)$ in the Se level was observed in HCD-fed groups as compared to respective controls in all the three Se status, i.e., deficient, adequate and excess groups. In deficient groups (Ia and $\mathrm{Ib}$ ) and in HCD fed adequate group, Se level decreased significantly $(\mathrm{p}<0.001)$, whereas in $1 \mathrm{ppm} \mathrm{Se}$ supplemented groups, the level increased significantly $(\mathrm{p}<0.001)$ after 2 months in comparison to 1-month data (Fig. 1). 


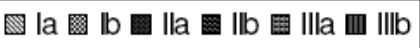

(a)

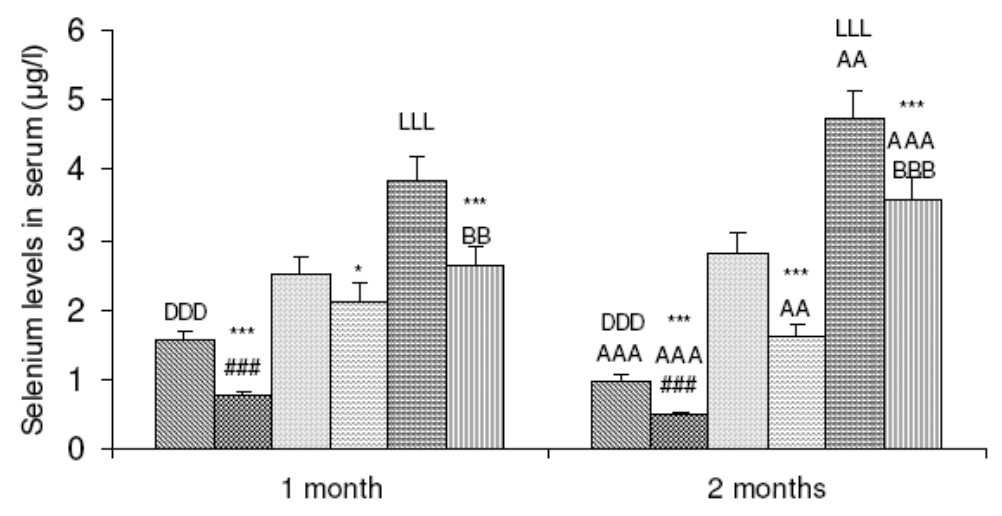

(b)

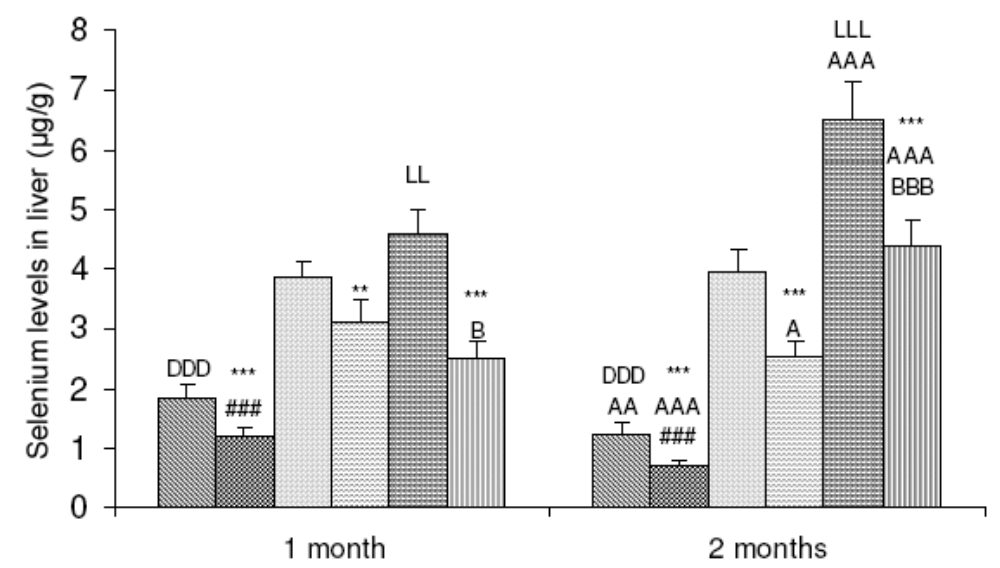

(c)

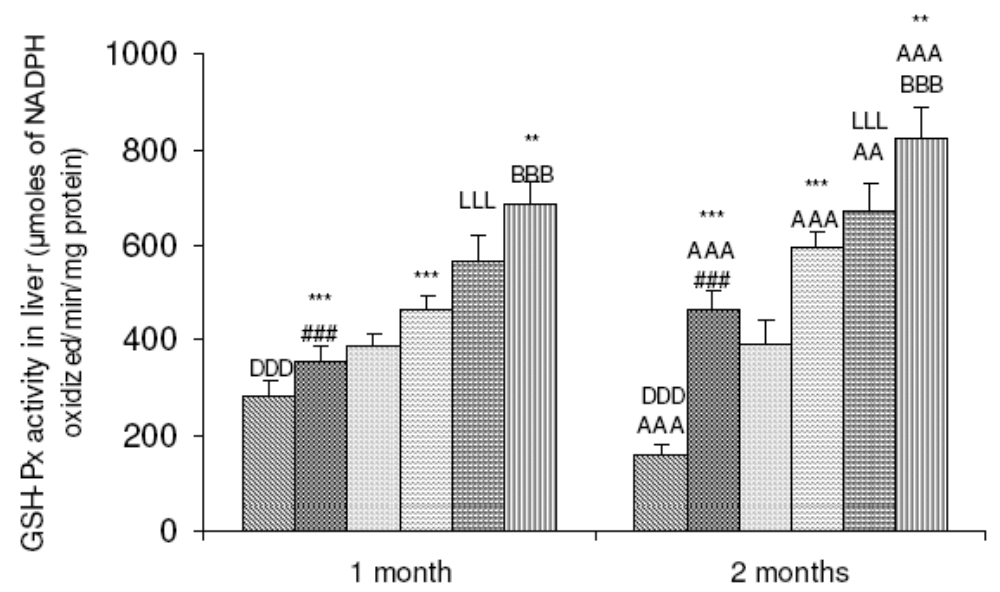

Figure 1: Selenium levels in serum and liver (a and b), hepatic GSH-Px levels (c), after 1 and 2 months, in different groups: Ia. Se-deficient control; Ib. Se-deficient+HCD; IIa. Se-adequate control; IIb. Se-adequate+HCD; IIIa. Se-excess control; IIIb. Se-excess+HCD,. Data is represented as mean \pm SD from 6 observations. ${ }^{*} p<0.05, * * p<0.01, * * * p<0.001$ represent comparison between control and HCD groups; A $p<0.05$, AA $p<0.01$, AAA $p<0.001$ comparison between 1 and 2 months; $\mathrm{DDD} p<0.001$ comparison between groups Ia and IIa; \#\#\#p<0.001 comparison between groups Ib and IIb; LL $p<0.01$, LLL $p<0.001$ comparison between groups IIa and IIIa; $\mathrm{B} p<0.05, \mathrm{BB} p<0.01$, $\mathrm{BBB} p<0.001$ comparison between groups IIb and IIIb. 


\section{GSH-Px activity}

GSH-Px activity in liver decreased significantly $(\mathrm{p}<0.001)$ in Se deficiency (Ia and $\mathrm{Ib}$ ), and it increased with $1 \mathrm{ppm} \mathrm{Se}$ supplementation (IIIa and IIIb) in comparison to the respective adequate groups (IIa and IIb). With HCD feeding, significant increase $(\mathrm{p}<0.001)$ was observed in all the groups in comparison to respective controls. In the Se-deficient control group, GSH-Px level decreased, whereas in HCD-supplemented Se-deficient and Se-adequate as well as Se-excess fed groups, the level increased significantly $(\mathrm{p}<0.001)$ after 2 months as compared to 1 month data (Fig. 1).

\section{Lipid profile}

In all the three Se status groups on HCD feeding, significant increase $(\mathrm{p}<0.001)$ in cholesterol and triglycerides concentration was observed in comparison to the respective control groups. In Se-deficient groups (Ia and $\mathrm{Ib}$ ), lipid level increased, and with $1 \mathrm{ppm}$ Se supplementation, it decreased significantly $(\mathrm{p}<0.001)$ in comparison to respective adequate groups (IIa and IIb). In both the Se-deficient groups (Ia and Ib) and in HCD-fed adequate group, lipid levels increased significantly $(\mathrm{p}<0.001)$, whereas they decreased with $\mathrm{Se}$ supplementation after 2 months in comparison to 1 month (Table 1).

\section{T3 and T4 levels}

Levels of $T_{3}$ decreased and $T_{4}$ increased significantly $(p<0.001)$ with HCD feeding in comparison to respective controls in all the three Se status groups. In Se deficiency (Ia and $\mathrm{Ib}), \mathrm{T}_{3}$ decreased and $\mathrm{T}_{4}$ level increased in comparison to respective adequate groups, whereas the reverse trend was observed with $1 \mathrm{ppm}$ Se supplementation, i.e., the $\mathrm{T}_{3}$ level increased and the $T_{4}$ level decreased significantly. In both the Se-deficient groups and in the HCD-fed adequate group (IIb) $\mathrm{T}_{3}$ decreased and $\mathrm{T}_{4}$ increased significantly, and in the Se-supplemented groups, $\mathrm{T}_{3}$ increased and $\mathrm{T}_{4}$ decreased after 2 months in comparison to 1 month (Table 1).
Type-I iodothyronine deiodinase (5'-DI) activity

5'-DI activity was estimated in liver, aorta, and thyroid. The activity decreased significantly $(\mathrm{p}<0.001)$ in HCD-fed animals in comparison to controls in liver and aorta. In Se deficiency, there was a significant $(p<0.001)$ decrease in the activity in comparison to respective adequate groups. The trend was just opposite in thyroid in Se deficiency as well with HCD feeding: the activity increased significantly $(\mathrm{p}<0.001)$. With $1 \mathrm{ppm}$ Se supplementation, the activity increased in all the tissues. The 5'-DI activity decreased in Se-deficient groups (Ia and $\mathrm{Ib}$ ), as well as in HCD-fed, adequate group, whereas it increased in $\mathrm{Se}$ supplemented groups after 2 months in comparison to 1-month data in liver and aorta. In thyroid, the activity increased in all the groups (except IIa) after 2 months in comparison to 1-month data (Table 2).

\section{Type-I iodothyronine deiodinase (5'-DI) mRNA expression}

RT-PCR products of expected size, i.e., $346 \mathrm{bp}$ and $236 \mathrm{bp}$, were obtained for 5'-DI and $\beta$-actin, respectively. mRNA expression in liver and aorta decreased $(\mathrm{p}<0.001)$ in Se-deficient groups (Figs. 2 and 3 ) in comparison to adequate groups (IIa and IIb). With HCD feeding, the mRNA expression decreased $(\mathrm{p}<0.001)$ in liver and aorta in all the selenium status groups (Figs. 2 and 3). However, as with enzyme activity, in thyroid tissue the trend was the opposite, i.e., mRNA expression increased in selenium deficiency, as well as with HCD feeding $(\mathrm{p}<0.001)$ (Fig. 4). With selenium supplementation, the mRNA expression increased significantly $(p<0.001)$ in all the tissues. The 5'-DI mRNA expression decreased in Sedeficient groups (Ia and Ib) as well as in HCD-fed adequate group, whereas it increased in Se-supplemented groups after 2 months in comparison to 1-month data in liver and aorta. In thyroid, the expression increased in all the groups (except IIa), after 2 months in comparison to 1 month (Figs. 2, 3 and 4). 


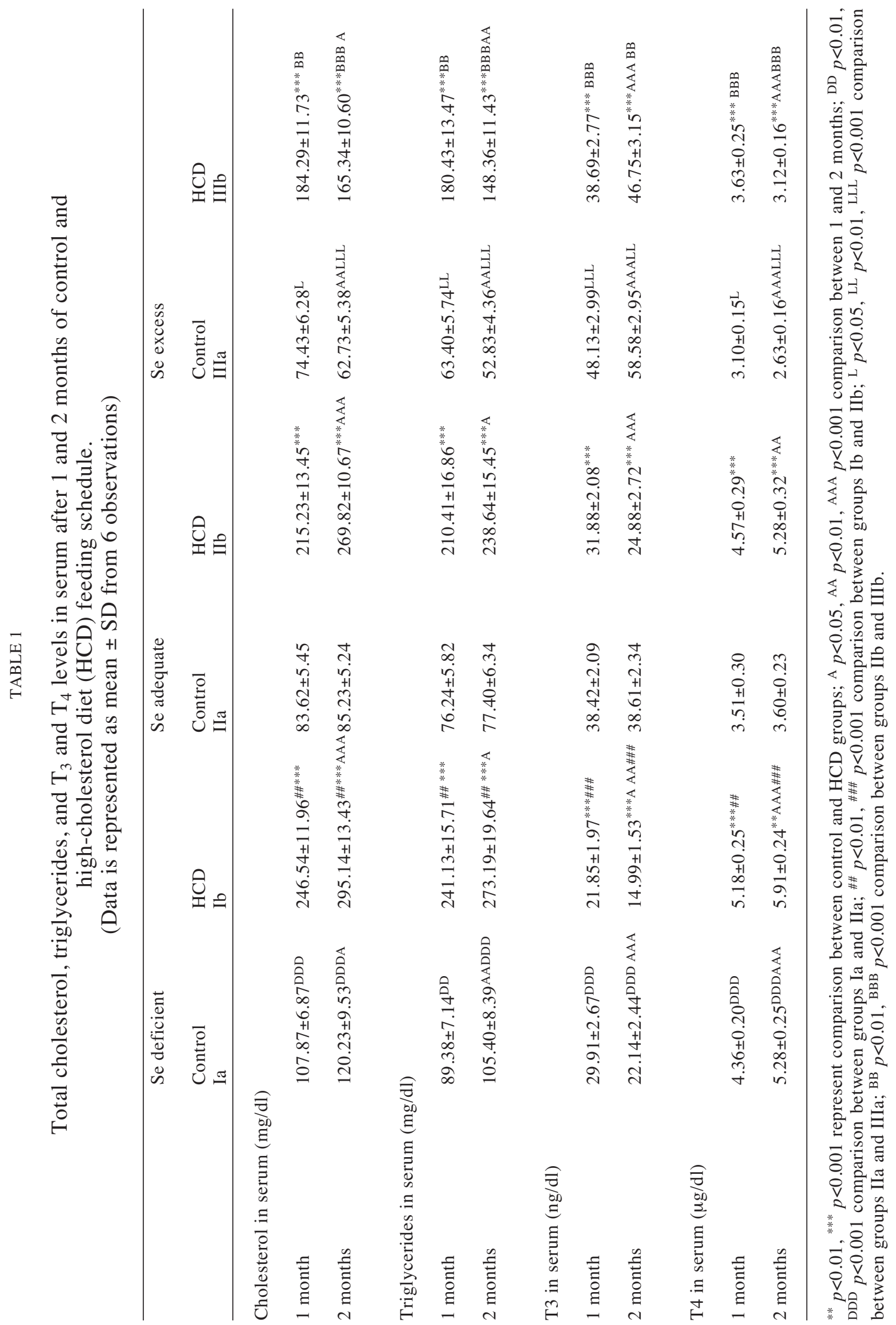




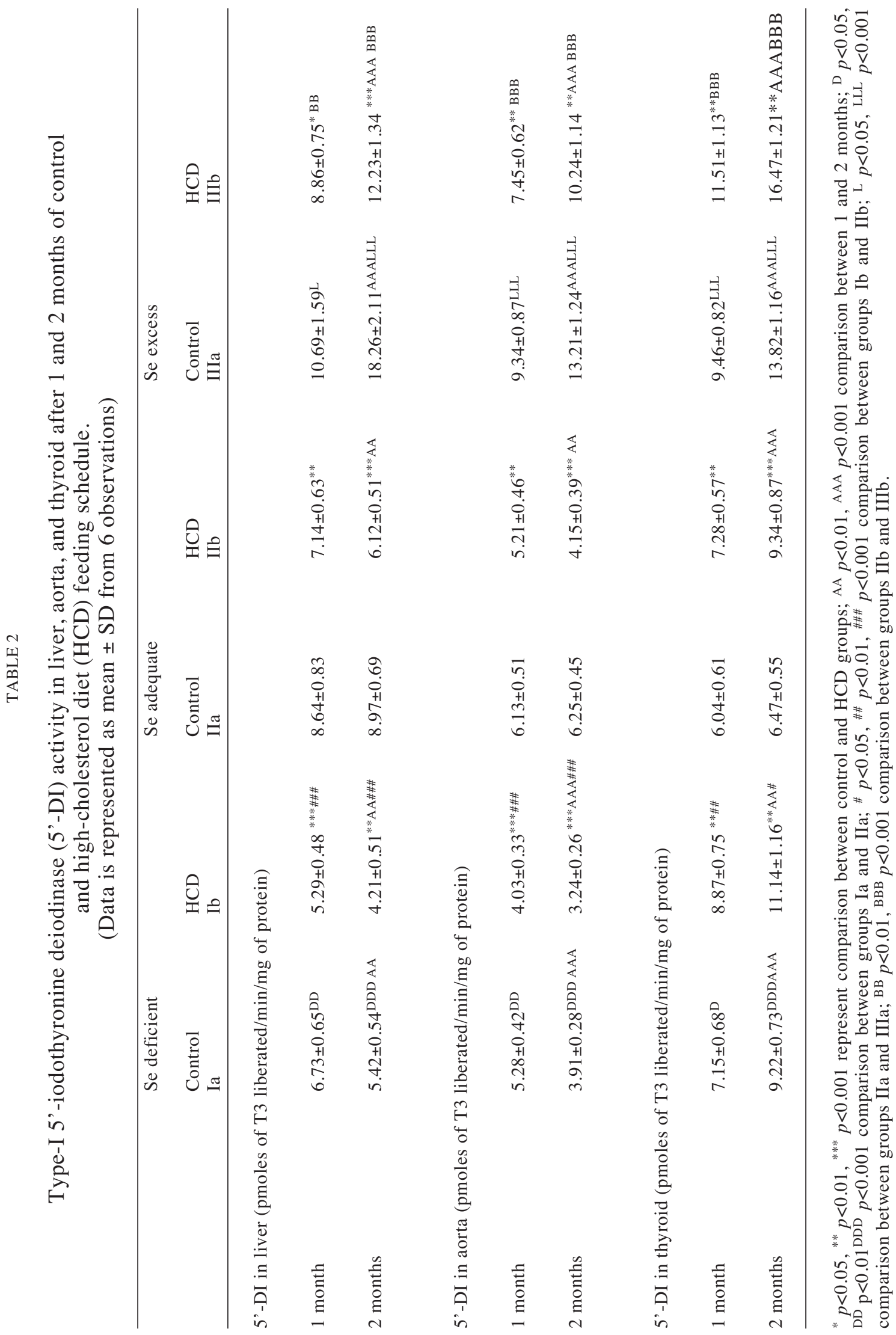


(a)

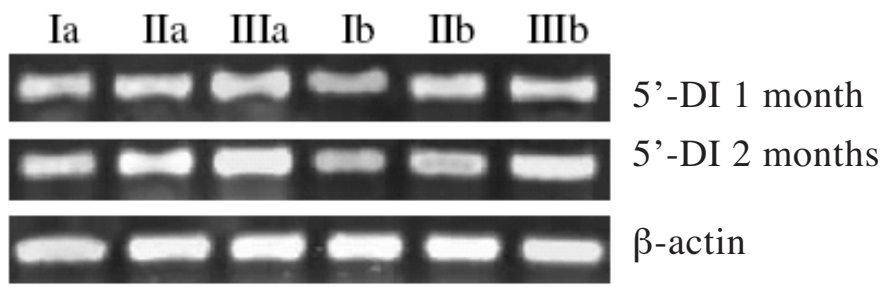

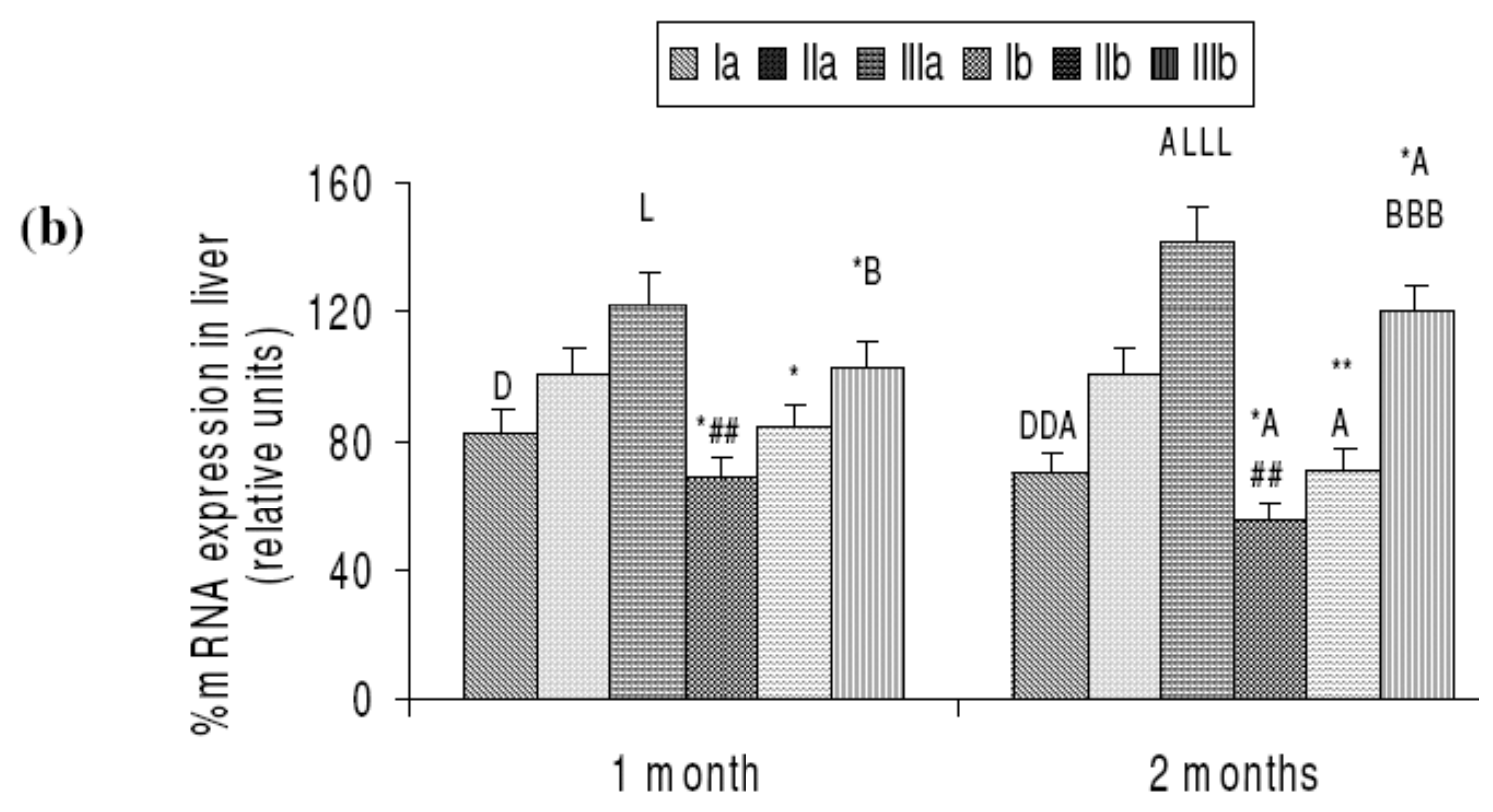

Treatm ent period

Figure 2: 5' -DI mRNA analysis in liver, after 1 and 2 months, in different groups: Ia. Se-deficient control; IIa. Se-adequate control; IIIa. Se-excess control; Ib. Se-deficient+HCD; IIb. Seadequate+HCD; IIIb. Se-excess+HCD. (a) mRNA expression by RT-PCR. (b) Expression was quantified by densitometric analysis. Data is expressed as mean \pm SD from 4 observations. $* p<0.05, * * p<0.01$ represent comparison between control and HCD groups; $\mathrm{A} p<0.05$ comparison between 1 and 2 months; $\mathrm{D} p<0.05$, DD $p<0.01$ comparison between groups Ia and IIa; \#\#p<0.01 comparison between groups Ib and IIb; L $p<0.05$, LLL $p<0.001$ comparison between groups IIa and IIIa; $\mathrm{B} p<0.05, \mathrm{BBB} p<0.001$ comparison between groups IIb and IIIb.

\section{DISCUSSION}

Present data demonstrate that HCD feeding leads to Se depletion in rats (Lee et al., 2003; Dhingra et al., 2005). In Se deficiency, significant increase in cholesterol and triglyceride level was observed in comparison to the animals fed adequate Se after 1 and 2 months (Table 1).
Low Se levels are associated with increased platelet aggregation and thromboxane A2 production along with decreased prostacyclin production, all of which may be linked with cardiovascular disease (Huang et al., 2002). With 1ppm Se supplementation, lipid levels decreased significantly in comparison to groups fed adequate Se (Kang et al., 2000). The Se 
(a)

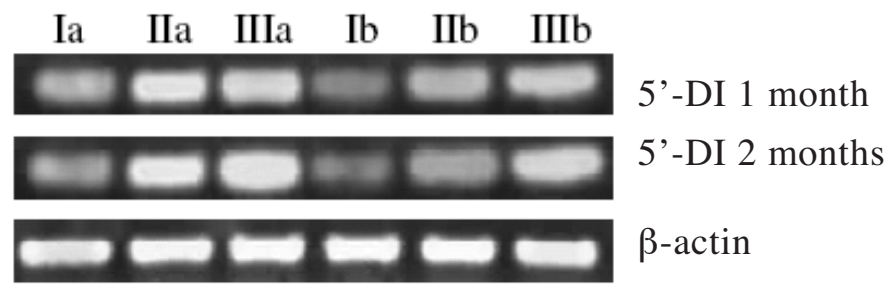

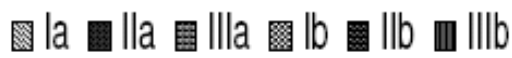

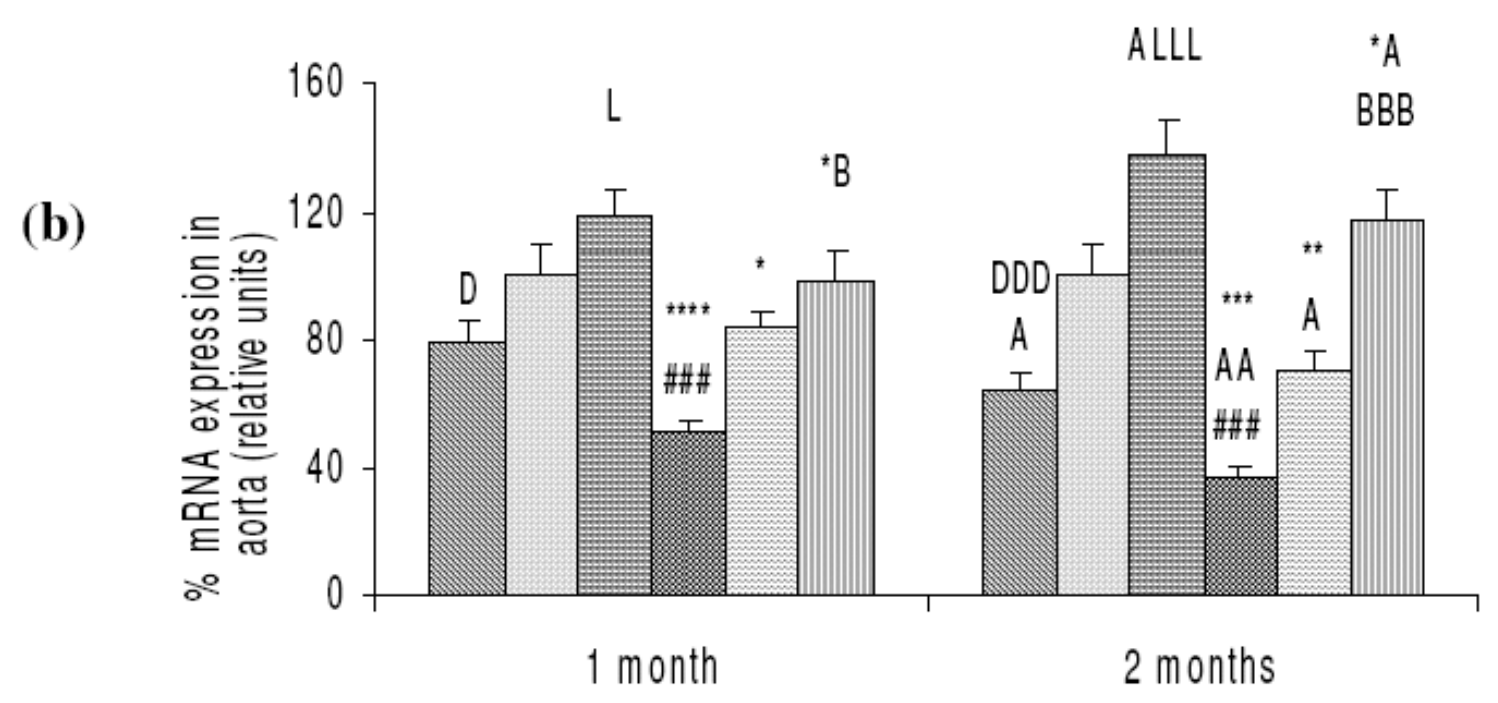

\section{Treatment period}

Figure 3: 5' -DI mRNA analysis in aorta, after 1 and 2 months, in different groups: Ia. Se-deficient control; IIa. Se-adequate control; IIIa. Se-excess control; Ib. Se-deficient+HCD; IIb. Seadequate+HCD; IIIb. Se-excess+HCD. (a) mRNA expression by RT-PCR. (b) Expression was quantified by densitometric analysis. Data is expressed as mean $\pm \mathrm{SD}$ from 4 observations. $* p<0.05, * * p<0.01, * * * p<0.001$ represent comparison between control and HCD groups; A $p<0.05$, AA $p<0.01$ comparison between 1 and 2 months; $\mathrm{D} p<0.05$, DDD $p<0.001$ comparison between groups Ia and IIa; \#\#\#p<0.001 comparison between groups Ib and IIb; L $p<0.05$, LLL $p<0.001$ comparison between groups IIa and IIIa; $\mathrm{B} p<0.05$, $\mathrm{BBB} p<0.001$ comparison between groups IIb and IIIb.

supplementation leads to an increase in HDL cholesterol fraction (Wojcicki et al., 1991). HDL cholesterol may downregulate the total cholesterol via reverse cholesterol transport to the liver, i.e., HDL fraction increases the cholesterol elimination from tissues including smooth muscle cells in the aorta wall and facilitates cholesterol transport to the liver, thus preventing its deposition and the formation of atheromatous plaque (Pelton et al., 2005).

The present results demonstrated that in Sedeficient groups, hepatic glutathione peroxidase (GSH-Px) activity decreased significantly in comparison to adequate groups (Fig. 1). In the Se-deficient control group, after 2 months the GSH-Px activity decreased in comparison to 1 month, so these observations 
(a)

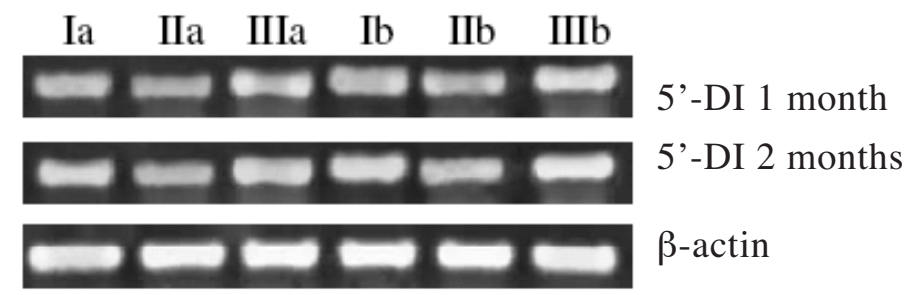

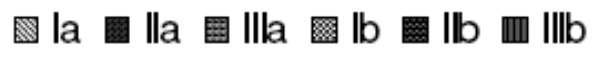

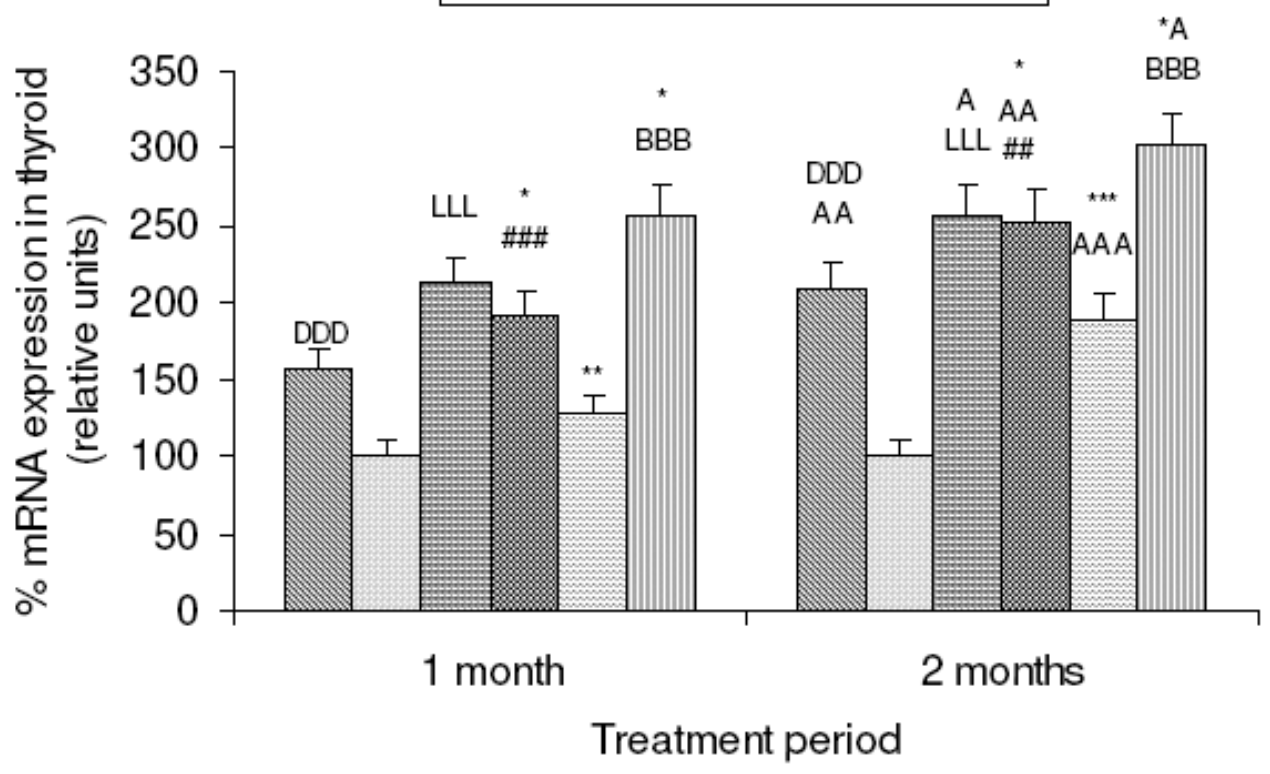

Figure 4: 5'-DI mRNA analysis in thyroid, after 1 and 2 months, in different groups: Ia. Sedeficient control; IIa. Se-adequate control; IIIa. Se-excess control; Ib. Se-deficient+HCD; IIb. Seadequate+HCD; IIIb. Se-excess+HCD. (a) mRNA expression by RT-PCR. (b) Expression was quantified by densitometric analysis. Data is expressed as mean \pm SD from 4 observations. ${ }^{*} p<0.05, * * p<0.01, * * * p<0.001$ represent comparison between control and HCD groups; A $p<0.05$, AA $p<0.01$, AAA $p<0.001$ comparison between 1 and 2 months; DDD $p<0.001$ comparison between groups Ia and IIa; $\# \# p<0.01$, \#\#\#p<0.001 comparison between groups Ib and IIb; LLL $p<0.001$ comparison between groups IIa and IIIa; $\mathrm{BBB} p<0.001$ comparison between groups IIb and IIIb.

confirm the Se deficiency (Arthur et al., 1993), which is associated with decreased GSH-Px activity. With HCD feeding, GSH-Px activity increased in all the groups. Further, it can be interpreted from our results that with cholesterol-rich diet feeding in all the Se status groups, GSH-Px activity increased after 2 months in comparison to 1-month data. This finding can be attributed to the increased lipoperoxidative stress associated with the HCD feeding, which concurs with the literature reporting elevation of GSH-Px activity as associated with a minor increase in oxidative stress (Kang et al., 2000). This increase in the Se-dependent GSH-Px with $\mathrm{HCD}$ feeding explains the decrease in the $\mathrm{Se}$ levels during hypercholesterolemia, as observed in the present study. 
The levels of $\mathrm{T}_{3}$ decreased and $\mathrm{T}_{4}$ increased significantly in Se deficiency as well as with HCD feeding (Table 1). This finding is probably due to the decreased conversion of $\mathrm{T}_{4}$ to $\mathrm{T}_{3}$ in the liver due to decreased 5'-DI expression during $\mathrm{Se}$ deficiency (Arthur el al., 1991; Dhingra et al., 2004). As observed in Se deficiency, increased plasma $\mathrm{T}_{4}$ levels usually upregulate the hepatic 5'-DI expression (Berry et al., 1990). In the current study, although plasma $\mathrm{T}_{4}$ levels are increased in Se deficiency, hepatic 5'-DI expression is diminished, presumably because the hepatic stores of Se are insufficient to allow the synthesis of 5'DI. However, the trend was the opposite with Se supplementation up to $1 \mathrm{ppm}$, i.e., $\mathrm{T}_{3}$ levels increased and $\mathrm{T}_{4}$ levels decreased; probably, with Se supplementation, increase in 5'-DI expression upregulated the $\mathrm{T}_{4}$ to $\mathrm{T}_{3}$ conversion.

With the selenium-deficient diet, 5'-DI activity as well as mRNA expression in liver and aorta decreased (Bermano et al., 1995) in comparison to the Se-adequate groups (Table 2; Figs. 2 and 3). On highcholesterol diet feeding, 5'-DI activity as well as mRNA expression decreased in liver and aorta. This finding could be due to the fact that hypercholesterolemia might have led to depletion in the Se pool, which is needed for normal 5'-DI expression. Another reason for this finding could be that hypercholesterolemia might be leading to hypothyroidism, which in turn downregulates the 5'-DI levels in liver and other peripheral tissues (Verhoelst et al., 2004). Furthermore, we have found a significant increase in 5' -DI activity as well as mRNA expression in liver and aorta with $1 \mathrm{ppm}$ Se supplementation. In cell culture experiments, Gross et al. (1995) have shown the clear dependence of 5'-DI expression on Se supply: enzyme activity as well as mRNA levels rapidly increased with the increase in Se concentration.

In contrast to liver and aorta, thyroidal 5'-DI activity and mRNA expression increased significantly with the highcholesterol diet feeding as well as in Se deficiency (Table 2; Fig. 4). This increased expression of thyroidal 5'-DI in Se deficiency confirms that thyroid is a higher priority tissue than liver and aorta for $\mathrm{Se}$ when intake of the element is very low, which is consistent with the fact that thyroid has the ability to retain a significant pool of trace element in Se deficiency (Behne et al., 1988). With 1ppm Se supplementation, 5'-DI activity and expression were further increased in thyroid. Beech et al. (1995) demonstrated that human thyrocytes grown in primary culture in a Se-free medium were able to retain the trace element to maintain the $5^{\prime}$ DI enzyme activity (the expression was further increased by the addition of Se to the diet). The increased 5'-DI expression in thyroid during a hypercholesterolemic state suggests that there is some compensatory mechanism that might get activated when 5 '-DI expression is downregulated in other peripheral tissues (liver and aorta). So, this tissue-specific differential behavior of $5^{\prime}$ DI might be maintaining the $\mathrm{T}_{3}$ level in the body during hypercholesterolemia. $\mathrm{T}_{3}$ is involved at the transcriptional level in the cardiovascular system. $\mathrm{T}_{3}$ enters into the cardiomyocytes through $\mathrm{T}_{3}$-binding nuclear receptors and interacts with specific transcriptional activators to modify the transcription rate of specific target genes (Brent, 1994). Thyroid hormones also decrease peripheral vascular resistance by promoting relaxation in vascular smoothmuscle cells (Park et al., 1997). Napoli et al. (2001) reported that thyroid hormones exert profound effects on the vascular system by improving both endotheliumdependent and -independent mechanisms.

The present data indicate that hypercholesterolemia along with the Se deficiency is co-responsible for tissuespecific differential expression of 5'-DI enzyme, i.e., the expression decreased in liver and aorta whereas it increased in thyroid. Until now, no direct association between 5'DI behavior and hypercholesterolemia has been observed. Thus, longitudinal studies to clarify the potential association between 5'DI expression and hypercholesterolemia under different Se status must be performed.

Further studies must be undertaken to explore the therapeutic role of $\mathrm{Se}$ supplementation in hypercholesterolemia through its dependent enzyme 5'-DI. 


\section{ACKNOWLEDGEMENTS}

Authors acknowledge the financial support given by Department of Atomic Energy, Government of India, Mumbai (India).

\section{REFERENCES}

ÁLVAREZ L, HERNÁNDEZ S, MARTÍNEZ-DE-MENA R, KOLLIKER-FRERS R, OBREGON MJ, KLEIMAN DE PISAREV DL (2005) The role of type I and type II 5' deiodinases on hexachlorobenzene-induced alteration of the hormonal thyroid status. Toxicology 207: $349-362$

ARTHUR JR, NICOL F, BECKETT GJ (1991) Hepatic iodothyronine deiodinase: The role of selenium. Biochem J 272: 537-540

ARTHUR JR, NICOL F, BACKETT GJ (1993) Selenium deficiency, thyroid hormone metabolism, and thyroid hormone deiodinases. Am J Clin Nutr 57: 236-239

BACKETT GJ, BEDDOWS SE, MORRICE PC, NICOL F, ARTHUR JR (1987) Inhibition of hepatic deiodination of thyroxine caused by selenium deficiency in rats. Biochem J 248: 443-447

BEECH SG, WALKER SW, BECKETT GJ, ARTHUR JR, NICOL F, LEE D (1995) Effect of selenium depletion on thyroidal type-1 iodothyronine deiodinase activity in isolated human thyrocytes, rat thyroid and liver. Analyst 120: 827-31

BEHNE D, HILMERT H, SCHIED H, GESSNER $H$, ELGER W (1988) Evidence for specific selenium target tissues and new biologically important selenoproteins. Biochem Biophys Acta 966: 12-21

BEHNE D, KYRIAKOPOULOS A, MEINHOLD $\mathrm{H}$, KOHRLE J (1990) Identification of type-1 iodothyronine 5'-deiodinase as a selenoenzyme. Biochem Biophys Res Commun 173: 1143-1149

BERMANO G, NICOL F, DYER JA, SUNDE RA, BECKETT GJ, ARTHUR JR, HESKETH JE (1995) Tissue-specific regulation of selenoenzyme gene expression during selenium deficiency in rats. Biochem J 311: 425-430

BERRY MJ, KATES AL, LARSEN PR (1990) Thyroid hormone regulates type I deiodinase messenger RNA in rat liver. Mol Endocrinol 4: 743-748

BERRY MJ, BANU L, LARSEN PR (1991) Type-1 iodothyronine deiodinase is a selenocysteine containing enzyme. Nature 349: 438-440

BRENT GA (1994) The molecular basis of thyroid hormone action. New Eng J Med 331: 847-853

BURK RF (1987) Production of selenium deficiency in the rat. Methods Enzymol 143: 307-313

DHINGRA S, SINGH U, BANSAL MP (2003) Protective role of selenium status on T3/T4 kinetics in rats under hyperlipidemia. Ind J Biochem Biophys 40: 260-264

DHINGRA S, SINGH U, BANSAL MP (2004) Effect of selenium depletion and supplementation on the kinetics of Type-I 5'-iodothyronine deiodinase and T3/T4 in rats. Biol Trace Ele Res 97: 95-104

DHINGRA S, BANSAL MP (2005) Attenuation of LDL receptor gene expression by selenium deficiency during hypercholesterolemia. Mol Cell Biochem (in press)

FRANK N, SOJKA JE, LATOUR MA (2004) Effect of hypothyroidism on the blood lipid response to higher dietary fat intake in mares. J Animal Sci 82: 26402646
GREEN WL (1978) Metabolism of thyroid hormones by rat thyroid tissue in vitro. Endocrinology 103: 826-837

GROSS M, OERTEL M, KOHRLE J (1995) Differential selenium-dependent expression of type I 5'deiodinase and glutathione peroxidase in the porcine epithelial kidney cell line LLC-PK1. Biochem J 306: 851-855

HASUNUMA R, OGAWI T, KAWANISKA Y (1982) Fluorimetric determination of selenium in nanogram amounts in biological materials using 2,3diaminonapthalene. Anal Biochem 26: 242-245

HUANG K, LIU H, CHEN Z, XU H (2002) Role of selenium in cytoprotection against cholesterol oxideinduced vascular damage in rats. Atherosclerosis 162: $137-144$

KANG BPS, MEHTA U, BANSAL MP (2000) Hyperlipidemia and type-I 5'-monodeiodinase activity: Regulation by selenium supplementation. Ind J Biochem Biophys 7: 183-187

KIMURA Y, YAMADA K, SAKAI T, MISHIMA K, NISHIMURA H, MATSUMOTO Y, SINGH M, YOSHIKAI Y (1998) The regulatory role of heat shock protein 70-reactive CD4+ $\mathrm{T}$ cells during rat listeriosis. Int Immunol 10: 117-130

KOHRLE J (1999) The trace element selenium and the thyroid gland. Biochimie 527-533

LEE O, MOON J, CHUNG Y (2003) The relationship between serum selenium levels and lipid profiles in adult women. J Nutr Sci Vitaminol (Tokyo) 49: $397-$ 404

LOWRY OH, ROSEBROUGH NJ, FARR AL, RANDALL RJ (1951) Protein measurement with Folin-phenol reagent. J Biol Chem 193: 265-275

MICHALOPOULOU G, ALEVIZAKI M, PIPERINGOS G, MITSIBOUNAS D, MANTZOS E, ADAMOPOULOS P, KOUTRAS DA (1998) High serum cholesterol levels in persons with "high-normal" TSH levels: should one extend the definition of subclinical hypothyroidism. Eur J Endocrinol 138: 141-145

NAPOLI R, BIONDI B, GUARDASOLE V MATARAZZO M, PARDO F, ANGELINI V, FAZIO S, SACCA L (2001) Impact of hyperthyroidism and its correction on vascular reactivity in humans. Circulation 104: 30763080

PAGLIA DE, VALENTINE WN (1967) Studies on the quantitative and qualitative characterization of erythrocyte glutathione peroxidase. J Lab Clin Med 170: $158-168$

PARK KW, DAI HB, OJAMAA K, LOWENSTEIN E, KLEIN I, SELLKE FW (1997) The direct vasomotor effect of thyroid hormones on rat skeletal muscle resistance arteries. Anesth Anal 85: 734-738

PELTON PD, PATEL M, DEMAREST KT (2005) Nuclear receptors as potential targets for modulating reverse cholesterol transport. Curr Topics Med Chem 265-282

PINGITORE A, LANDI P, TADDEI MC, RIPOLI A, L'ABBATE A, IRVASI G (2005) Triiodothyronine levels for risk stratification of patients with chronic heart failure. Am J Med 118: 132-136

SIEGMUND W, SPIEKER K, WEIKE AI, GIESSMANN T, MODESS C, DABERS T, KIRSCH G, SANGER E, ENGEL G, HAMM A O, NAUCK M, MENG W (2004) Replacement therapy with levothyroxine plus triiodothyronine (bioavailable molar ratio $14: 1$ ) is not superior to thyroxine alone to improve well-being and cognitive performance in hypothyroidism. Clin Endocrinol (Oxf) 60: 750-757

VANDER GEYTEN S, BYAMUNGU N, REYNS GE, KUHN ER, DARRAS VM (2005) Iodothyronine deiodinases and the control of plasma and tissue 
thyroid hormone levels in hyperthyroid tilapia (Oreochromis niloticus). J Endocrinol 184: 467-479

VERHOELST CH, DARRAS VM, DOULABI BZ, REYNS G, KUHN ER, VANDER GEYTEN S (2004) Type I iodothyronine deiodinase in euthyroid and hypothyroid chicken cerebellum. Mol Cel Endocrinol 214: 97-105

WASSEN FW, KLOOTWIJK W, KAPTEIN E, DUNCKER DJ, VISSER TJ, KUIPER GG (2004) Characteristics and thyroid state-dependent regulation of iodothyronine deiodinases in pigs. Endocrinology 145: 4251-4263

WOJCICKI J, ROZEWICKA L, WISZNIEWSKA BB, SAMOCHOWIEC L, JUWIAK S, KADLUBOWSKA D, TUSTANOWSKI S, JUZYSZYN Z (1991) Effect of selenium and vitamin $\mathrm{E}$ on the development of experimental atherosclerosis in rabbits. Atherosclerosis 87: 9-16 